\title{
Toxics Release Inventory - An Environmental Database
}

\section{Data Background/Description}

This paper describes a publicly available database called the Toxics Release Inventory (TRI), which provides a valuable data source of environmental information. The TRI data are machinereadable microdata at the industrial facility level and are provided free with unlimited access to the public. The data collection approach for this database is innovative because it uses the information collection provision as the regulatory instrument.

Following a chemical-release accident in Bhopal, India, the U.S. Congress passed the Emergency Planning and Community Right-to-Know Act (EPCRA) in 1986. Under these provisions, manufacturing facilities with 10 or more employees in Standard Industrial Classification (SIC) codes 20 through 39 are required to publicly disclose their annual toxic release to air, water, and land as well as off-site transfers. The U.S. Environmental Protection Agency (EPA) compiled these annual reports into the TRI database. Because of the mandatory requirement of data provision and its inclusion of a public's right-to-know provision, this database provides a reliable source of environmental performance information.

Since the initial data release in 1989, the number of reporting facilities and chemicals has been increased. Seven industrial sectors have been added to the original reporting manufacturing industries. These include electric utilities, coal mining, metal mining, chemical wholesalers, petroleum bulk plants and terminals, solvent recovery and hazardous waste treatment, storage, and disposal. New data for 1998 were released in 2000 covering seven industrial sectors. There is a two-year time lag in the release of TRI data. For example, the most recent data release in 2000 is for the reporting year 1998.

The TRI data have become a primary source of environmental performance information for a broad range of user groups. These include social scientists, environmentalists, government officials, investors, consulting firms, journalists, health professionals, etc. The international organizations have also recently joined the group of TRI users.

\author{
Data Dissemination/Search Engines \\ Data Access \\ Technological progress has brought \\ major changes in data management and \\ data analysis system. The data storage \\ and data access are much easier due to \\ the faster speed of personal or mainframe \\ computers, larger data storage capacities \\ and the development of the Internet.
} Accessibility and media format options for the TRI have also changed. The TRI data are currently available on floppy diskette, CD-ROM, or through the Internet.

The floppy diskettes contain the most frequently used data elements including each facility's identification numbers, county, city, state, zip code, SIC code, parent company name, chemical name and chemical registry number, total releases to the air, water, land, underground injection and off-site transfers. They also include the longitude and latitude of the facility and Federal Information Processing Standards (FIPS) code. The CD-ROM edition is comprised of two CDs. Disc one has the TRI data for 1987-1990. Disc two contains data for 1991-1996. The basic features of the CD-ROM include: user guide, combining searches using Boolean operators, displaying records, exporting records in several formats, creating custom reports and calculating the data using KASTAT. The TRI data on the Internet is available for the time span of 1988-1998.

\section{TRI Explorer}

The TRI Explorer is a search engine that provides access to the TRI data on the Internet. The initial version of the TRI Explorer included on- and off-site release data. The latest version added waste transfer and waste management data to the original toxic release data. This search engine allows you to identify facilities and their chemical release. Data can be disseminated into release, waste transfer and waste quality reports. Data can be grouped according to five criteria: facility, chemical, year or industry type and geographic area at the county, state or national level. Waste management reports include recycling, energy recovery, treatment as well as off-site waste transfers. A trends report option is also available for the core chemicals. Metadata on the web provides valuable information including detailed data element descriptions. Data elements provide both facility identification information and chemical-specific information. 
Other TRI Sites on the Internet

On-line searching for the TRI data is available using the web sites such as Envirofacts: Data Warehouse and Applications and the National Library of Medicine (NLM) TOXNET System. The Envirofacts Warehouse includes multiple environmental databases that allow you to retrieve environmental information from several EPA databases. Spatial data are available using the Maps on Demand applications. TOXNET (Toxicology Data Network) is a cluster of databases on toxicology, hazardous chemicals, and other related environmental or public health areas.

\section{International Development Systems}

\section{International TRI-like System}

There has been a growing global movement for information database on toxic release. International TRI-like system is called as Pollutant Release and Transfer Registers (PRTRs). International organizations started some initiatives to implement the development of PRTRs. The PRTRs in the world include: Canada: National Pollutant Release Inventory (NPRI), United Kingdom: Pollutant Inventory (PI), Mexico: Registro de Emisiones y Transferencia de Contaminantes (RETC), Australia: National Pollutant Inventory (NPI) and Czech Republic: Pollutant Release and Transfer Register (PRTR). Among three North American PRTRs, Canada has PRTR data starting 1993. Mexico collects PRTR data from industrial facilities on a voluntary basis. The Commission for Environmental Cooperation (CEC), an environmental organization created by the North American Free Trade Association (NAFTA), compiles the data and publishes an annual report on the North American PRTRs.

Asian countries also participated in this international movement. Japan hosted the most recent international conference on PRTRs: National and Global Responsibility in September 1998. Indonesia developed similar public disclosure program called Program for Pollution Control, Evaluation and Rating (PROPER). Indonesia's National Pollution Control Agency initiated this pollution control program to evaluate the environmental performance of Indonesian factories. The Philippines followed Indonesia's footsteps. The Philippines' Department of Environment and Natural Resources recently started a public disclosure program called EcoWatch modeled on Indonesia's PROPER program.

\section{International Organization PRTR Sites}

The international movement on PRTRs stems from the 1992 Earth Summit, also called the United Nations Conference on Environment and Development (UNCED). Several international organizations now have their own home page for the development of PRTRs: Organization for Economic Co-operation and Development (OECD) PRTR homepage, United Nations Environmental
Programme (UNEP) PRTR homepage, UNITAR PRTR homepage and World Bank PRTR homepage.

\section{Further Data Usability}

Growing international interest in toxic release information presents the opportunity to combine the various databases and compare each country's toxic releases and waste management activities. It also provides the possibility of developing an international toxic release database in the future. This would be in addition to the existing data archives and would be beneficial both to academic researchers and government policy makers. Wide use of this database will also provide industries with the incentive to improve existing pollution abatement technology.

In addition to the unified international database, it is suggested that a comprehensive database may be developed using existing databases from other areas. One such area is public health, where human health risks could be measured using the TRI and other health information databases. Other health information databases include the Hazard Information on Toxic Chemicals, Integrated Risk Information System (IRIS), and ToxFAQs ${ }^{\mathrm{TM}}$ by the Agency for Toxic Substances and Disease Registry (ATSDR). Another areas are finance and economy, where the financial effects of environmental information can be assessed using the financial databases. They include the Center for Research in Security Prices (CRSP) database and the Standard \& Poor's Compustat database.

\section{Conclusion}

The Toxics Release Inventory database is a valuable resource as a database for researchers in the area of environmental studies, health and business. In addition, it provides policy makers and the public with a reliable source of information on toxic emissions and serves as a regulatory tool for the management of industrial pollutants. In addition, the availability of TRI data along with similar efforts in other countries provides an incentive for cooperative efforts in international reporting and analysis of toxic release data.

* Mary J. Lee, 945 Flanner Hall, Laboratory for Social Research, University of Notre Dame, Notre Dame, IN 46556 U.S.A. Tel (219) 631-4521 E-mail: Lee.82@nd.edu 